\title{
KLEPTOMANIA, MOOD DISORDER AND LITHIUM
}

\author{
FÁBIO LOPES ROCHA * - MARIA ELIZABETE GUIMARÃES ROCHA **
}

SUMMARY - Kleptomania has been found in association with major depression in a fairly large number of reports in recent years. We describe a patient with concurrent DSM-III-R Bipolar Mood Disorder and Kleptomania, whose symptoms remitted completely, apparently in response to lithium therapy, which raised the possibility that pharmacological treatment may benefit kleptomania. Further studies are needed to establish the possible relationship between kleptomania, mood disorders and lithium therapy.

KEY WORDS : kleptomania, lithium, mood disorders, bipolar disorder.

Cleptomanía, disturbio do humor e litio

RESUMO - Os autores descrevem e comentam o caso de urna paciente com Distúrbio de Humor Bipolar e Cleptomanía (DSM-III-R) que apresentou remissão de seu quadro compulsivo após instituição de litioterapiia. Discuttem al prossithintidltadle dio tratamento medicamentoso para este distúrbio e apontam para a necessidade de estudos que estabeleçam a eventual relação entre cleptomanía, distúrbios do humor e litioterapia.

PALA VRAS-CHAVE: cleptomanía, lítio, distúrbios do humor, distúrbio bipolar.

According to DSM-III-R', the essential feature of kleptomania is a recurrent failure to resist impulses to steal objects not needed for personal use, often worthless and easily obtainable by legitimate means. Commonly the person experiences an increasing sense of tension before committing the act, relief while committing it and, not rarely, feelings of guilt or self reproach afterwards. Kleptomania has been frequently described in association with depression 2,3,6,8,10. It is extremely rare. Only $5 \%$ of all shoplifters referred to forensic psychiatric examination are kleptomaniacs. It is more common in females than in males $7,9$. Age of onset is variable; it may begin in childhood or adolescence. The course is often chronic. It usually waxes and wanes and it is not known how often remission occurs 9.

The aim of this study is to discuss the relationship between kleptomania and mood disorders and the possible action of lithium in its treatment.

\section{CASE REPORT}

MIAF, a 51-year-old, married female, with 4 male children and a university degree in Education, had a 27-year history of psychiatric treatment. By the time (1983) of her first psychiatric evaluation with our Service, in search of a new treatment, she displayed depressive symptoms. She informed the onset of symptoms at age 24, after her house had been broken into. She developed persecutory ideas and aggresive behavior. She went into psychoanalysis for 3 years then. Nine years later (at ago 33), she had la second episode, characterized by ag-

* Psychiatrist, Preceptor of Psychiatry of thei Psychiatric Residency, Hospital das Clínicas, Universidade Federal de Minas Gerais; Hospital Galba Velloso, Fundação Hospitalar do Estado de Minas Gerais. ** Psychiatrist, Staff Member of the Mental Health Program, Fundação Ezequiel Dias, Secretaria de Saúde do Estado de Minas Gerais.

Dr. Fábio Lopes Rocha - Av. Brasil 69S/202 - 30140 Belo Horizonte MG - Brasil. 
gressiveness and the suspicion that people actually knew what she was thinking. She also gave special, particular and unapprehensible significance to colors. At the ages of 18 land 50, respectively, she went through two additional major episodes with the same features. She received ECT treatment, then. All along she had been treated with pharmacological agents, (antidepressants and antipsychotics (haloperidol, trifluoperazine, chlorpromazine, nomifensine, amitryptiline and biperidene). Between the phases, she informed of never feeling very well, displaying irritable or depressive moods and suspiciousness. Concurrently, starting at age 33, she developed a compulsive behavior for small thefts, outstanding for the worthlessness and uselessness of the objects, as far as monetary value or personal use are concerned. She experienced an increasing excitation, just before and throughout the act, but straightforwardly, she felt guilty or fearful of being detected. During the several courses of treatment undertaken by the patient prior to our evaluation, she received diagnoses of schizophrenia, atypical or non-especific psychoses with schizophrenic features. Two other hypotheses were raised during her current treatment with us (and from our standpoint, both were confirmed by follow-up): (a) bipolar mood disorder with mood-incongruent psychotic features; b) kleptomania.

Treatment and evolution - Psychopharmacological therapy was started with an increase of the daily dosage of amitriptyline up to $100 \mathrm{mg} / \mathrm{day}$ and the maintenance of an antipsychotic drug in a low dosage (haloperidol, $1 \mathrm{mg} / \mathrm{day}$ ), based on her previous history of psychosis. Simultaneously, she started a supportive psychotherapy with analytical orientation in a frequency of one session per week. Her illness progressed with frequent mood swings, changing directions bimonthly or monthly, which forced us to also frequent alterations in her medication, although these oscillatory periods have never reached the intensity of the preceding relapses, most probably due to earlier detection and faster interventions. Kleptomanic behavior followed all along almost continuously, although it lessened during depression or paradoxically, throughout euphoric moods. At this stage of treatment, she wias apprehended throe times, which always led her to deep feelings of shame and guilt and to pledges of self control for her impulses. She managed all three situations without being prosecuted, though. She gradually developed a high tolerance to the antidepressant agent, demanding an ever increasing dosage (up to $200 \mathrm{mg} / \mathrm{day}$ ) to maintain therapeutic effects during her depressive periods.

Almost 1 1/2 year later, with the consolidation of the hypothesis of Bipolar Mood Disorder with Mood Incongruent Psychotic Features, and seeing as how it became quite difficult to stabilize the patient's mood, and due to the development of tolerance to amitriptyline, the patient agreed to an alteration of her treatment. Her reluctance was due to the fact that, in spite of the persistence of her mood swings, she had never felt so well as in these last period. We prescribed lithium in the dosage of $1200 \mathrm{mg} / \mathrm{day}$ (serum level of $0.8 \mathrm{mElq} / \mathrm{L}$ after steady state). Very gradually, her mood swings improved, and within 30 months, enduring stability was achieved, although a low dosage of antidepressant was necessary to avoid depression. The patient has had no recurrences foi the last two years. A remarkable finding was that kleptomania improved significantly. After a 20 year evolution with the maintenance of the pathological behavior most of the time, the picture remitted within the first month of lithium therapy, long before remarkable clinical changes in mood. For the last 3 1/2 years she has not committed any thefts and has remained free of experiencing the impulses to steal.

\section{COMMENTS}

The classical conception of kleptomania remains in the domain of the psychoanalytical approach. In this frame, it has been considered a behavior with a symbolic meaning, linked to ungratified sexual instincts, including a risk-taking attitude substitute of masturbation or a reclaiming lost affection 5,7. More recent analytical studies have emphasized the aggressive rather than the libidinal aspects of this behavior. * 7 . Others have described kleptomania as a risk-taking attitude in response to depression 6.

Kleptomania has been classified within the Disorders of Impulse Control in the DSM-III-R, and as such, it is considered a nosological entity. On the other hand, some authors have dealt with kleptomania using vague taxonomic categories to classify it, mentioning it as belonging to disorders of behavior, linked to epilepsies, to anti-social personality, perversions and obsessive-compulsive neurosis $\mathbf{4 , 5}$. Some recent studies hint at the possibility that kleptomania may be a symptom; depression or another mood disorder being the underlying illness ${ }^{2} .^{316}$. 
While conducting our own case, the remission of kleptomania after lithium therapy brought up a number of hypotheses, to be discussed: (a) that kleptomania remitted due to its natural course, independent of therapeutics; (b) that the remission was an inespecific response due to the introduction of new therapeutics; (c) that kleptomania remitted due to life events; (d) that the remission was due to psychotherapy; (e) that kleptomania might be, in some cases, related to mood disorders, being a symptom of theirs and, in these cases, responsive to lithium therapy; (f) that lithium might have a direct impact upon kleptomania; (g) that lithium might have an especific action upon impulsivity and lack of self-control.

A remarkable fact in the evolution of our patient is that kleptomania remitted shortly after the start of lithium therapy, long before the improvement of the mood disorder. Another important fact is that all of the previous treatments were absolutely ineffective upon the kleptomaniac behavior. One could consider that kleptomania actually had remitted spontaneously, which might have happened, but due to the chronic course of this disorder before the start of lithium therapy and the extended period of remission since then, this alternative seems unlikely.

An inespecific response to a new therapeutic approch, due to the expectations of the physician, the patient or the environment, must always be considered, but in this case the intention was not related to the remission of kleptomania, which occurred, in fact, unexpectedly.

She had not experienced any significant life event in the last months before the remission of kleptomania behavior. Apprehension does not seem to have jplayed a meaningful part in the picture, since the patient went through three such situations, the first time (or the second) neither avoiding the following act nor attenuating the impulse.

A response to psychotherapy must be pondered, but the fact that the patient had previously undergone psychoanalysis during three years without improvement and that she showed no response of the kleptomaniac behavior when this theme was exhaustively treated in the beginning of her supportive therapy, turne this hypothesis quite unprobable.

Whether kleptomania is, in some cases, a symptom of mood disorders and in this way responds to antidepressants, this is a hypothesis with some evidence in the literature. There is at least one report in which kleptomania has been described accompanying bulimia and depression and some evidence that kleptomania related to these two clinical entities responds satisfactorily to antidepressants 8, raising the question of whether bulimia and kleptomania may be aspects of mood disorders, although not usually considered as such. Fishbain^ ${ }^{\wedge}$ described a patient suffering from depression and kleptomania that remitted with ECT or antidepressants associated with psychotherapy.

A direct impact of lithium upon kleptomaniac behavior is an assumption that would require a double-blind trial to be proved.

A hypothesis that has a great appeal to us is that one of the specific actions of lithium therapy upon impulsivity and lack of self-control. A number of anecdotal case reports and some better controlled studies have claimed that lithium evoked good therapeutic response in conditions like: conduct disorders with explosive temper outbursts and fighting, borderline personality disorder, bulimia, pathological gambling, trichotillomania and intermittent explosive disorder $^{\wedge}{ }^{12}$. All these disorders present a commom feature, that is, a disturbance of the impulse control. Roy et al. ${ }^{11}$, investigating psychobiological substrate of pathological gambling, found a significantly higher centrally produced fraction of cerebrospinal fluid levels of 3-MHPG, as well as significantly greater urinary outputs of norepinephrine than controls. The results raised the possibility that pathological gamblers might have a disturbance in their noradrenergic system, in accordance with Zuckerman's hypothesis (apudii) that the personality trait of sensation-seeking may underlie risk-taking behavior, and that the biological substrate associated may be an increased tonic activity of the central noradrenergic system. We can question whether kleptomania has a psychobiological substrate, 
the same as pathological gambling or other disturbances, that could be modified by lithium therapy.

In summary, although great caution should be observed in drawing conclusions from a case study, a close relation between kleptomania, mood disorder and lithium therapy has been eluded in this report.

Unfortunately (or fortunately), kleptomania is a rare problem. This fact brings up several difficulties to systematic, controlled studies. To date, kleptomania has been described on a case-study basis only. The knowledge of this clinical entity remains scant. Most case reports in the literature have focused on psychodynamic psychotherapy. Maybe the more recent reports that communicate improving of kleptomaniac behavior under biological and pharmacological treatments may contribute to a better knowledge of this disorder and to new perspectives in its treatment. We think that the yet available data concerning pharmacological treatment of kleptomania support future efforts to the development of systematic, controlled trials.

Acknowledgments - We pay tribute to Mr. David K. Bowen, BSW, MA, for his patience and time reviewing the text.

\section{REFERENCES}

1. American Psychiatric Association. Diagnostic and Statistics Manual of Mental Disordeis. Ed 3 (Revised) Washington: American Psychiatric Press, 1987.

2. Bradford J, Balmaceda R. Shoplifiting: is there a specific psychiatric syndrome? Can J Psychiatry 1983, 28:248-254.

3. Davis H. Psychiatric aspects of shoplifting. S A Med J 1979, 55:885-887.

4. Ey H, Bernard P, Brisset C. Manual de Psiquiatria. Rio: MJasson do Brasil, 1981.

5. Fenichel O. Teoria Psicanalítica das Neuroses. São Paulo: Ateneu, 1981.

6. Fishbain DA. Kleptomania as risk-taking behavior in response to depression. Am J Psychoter 1987, 41:598-603.

7. Gibbens TCN. Shoplifting. Br J Psychiatry 1981, 138:341-347.

8. McElroy SL, Keck PE, Pope HG Jr, Hudson JI. Pharmacological treatment of kleptomania and bulimia nervosa. J Clin Psychopharmacol 1989, 9:358-360.

9. Popkin MK. Impulse control disorders not elsewhere classified. In Kaplan HI, Sadock BJ (eds): Comprehensive Textbook of Psychiatry. Ed 5. Baltimore: Williams \& Wilkins, 1989, p 1145.

10. Ramelli E, Mapelli G. Du vol mélancolique. Acta Psychiat Belg 1979, 79:56-74.

11. Roy A, Adinoff B, Roehrich L, Lamparski D, Custer R, Lorenz V, Barbaccla M, Guidotti A, Costa E, Linnoila M. Pathological gambling: a psychobiological study. Arch Gen Psychiatry 1988, 369-373.

12. Sargent M. Treating nonaffective disorders with lithium. Hosp Comm Psychiatry 1989, 40:579-581. 